\title{
A cross-sectional retrospective analysis of the regionalization of complex surgery
}

\author{
James Studnicki ${ }^{1 *}$, Christopher Craver $^{2}$, Christopher M Blanchette ${ }^{1}$, John W Fisher ${ }^{1}$ and Sara Shahbazi ${ }^{2}$
}

\begin{abstract}
Background: The Veterans Health Administration (VHA) system has assigned a surgical complexity level to each of its medical centers by specifying requirements to perform standard, intermediate or complex surgical procedures. No study to similarly describe the patterns of relative surgical complexity among a population of United States (U.S) civilian hospitals has been completed.
\end{abstract}

Methods: Design: single year, retrospective, cross-sectional. Setting/Participants: the study used Florida Inpatient Discharge Data from short-term acute hospitals for calendar year 2009. Two hundred hospitals with 2,542,920 discharges were organized into four quartiles $(Q 1,2,3,4)$ based on the number of complex procedures per hospital. The VHA surgical complexity matrix was applied to assign relative complexity to each procedure. The Clinical Classification Software (CCS) system assigned complex procedures to clinically meaningful groups. For outcome comparisons, propensity score matching methods adjusted for the surgical procedure, age, gender, race, comorbidities, mechanical ventilator use and type of admission. Main Outcome Measures: in-hospital mortality and length-of-stay (LOS).

Results: Only $5.2 \%$ of all inpatient discharges involve a complex procedure. The highest volume complex procedure hospitals (Q4) have $49.8 \%$ of all discharges but 70.1\% of all complex procedures. In the 133,436 discharges with a primary complex procedure, 374 separate specific procedures are identified, only about one third of which are performed in the lowest volume complex procedure (Q1) hospitals. Complex operations of the digestive, respiratory, integumentary and musculoskeletal systems are the least concentrated and proportionately more likely to occur in the lower volume hospitals. Operations of the cardiovascular system and certain technology dependent miscellaneous diagnostic and therapeutic procedures are the most concentrated in high volume hospitals. Organ transplants are only done in Q4 hospitals. There were no significant differences in in-hospital mortality rates and the longest lengths of stay were found in higher volume hospitals.

Conclusions: Complex surgery in Florida is effectively regionalized so that small volume hospitals operating within the range of complex procedures appropriate to their capabilities provide no increased risk of post surgical mortality.

Keywords: Surgical complexity, Surgical outcomes, Regionalization of surgical services

\section{Background}

Any evaluation of surgical outcomes must consider the influence of the relative complexity of the surgical procedures. Surgical complexity has been conceptualized and measured largely by addressing both intraoperative factors and patient risk factors. Intraoperative factors considered to influence surgical complexity include blood loss, duration of the surgery, technical expertise required

\footnotetext{
* Correspondence: jstudnic@uncc.edu

'Department of Public Health Sciences, College of Health and Human

Services, University of North Carolina, Charlotte, NC, USA

Full list of author information is available at the end of the article
}

of the surgeon, invasiveness of the procedure, organ system involvement, existing pathology and required technical equipment [1-14]. Patient characteristics, most notably age and co-morbid conditions, are strongly associated with operative complexity $[5,11,12,15-20]$. Existing research consistently relates procedural complexity to multiple outcomes such as increased mortality and morbidity, greater length of stay, increased likelihood of a readmission, longer time in intensive care and higher overall costs $[1,3,4,8,9,12,19,21-30]$.

\section{Biomed Central}

(c) 2014 Studnicki et al.; licensee BioMed Central Ltd. This is an Open Access article distributed under the terms of the Creative Commons Attribution License (http://creativecommons.org/licenses/by/2.0), which permits unrestricted use, distribution, and reproduction in any medium, provided the original work is properly credited. 
While hospital and surgeon volumes have been revealed to be important determinants of surgical outcomes, the volume-outcome relationship deserves particular emphasis for complex procedures since they are performed in small numbers overall and typically constitute only a small proportion of hospital total caseloads. Policy experts, insurance companies, coalitions of purchasing groups and others advocate that patients needing complex surgical procedures should be referred to hospitals with the best outcomes, particularly high volume facilities $[1,9,26,29,31]$.

Perhaps the best example of a large-scale application of these concepts comes from the VHA and its National Surgical Quality Improvement Program (NSQIP), which developed a validated risk-adjusted model to predict surgical outcomes. The predictive model included a measure of surgical complexity [32]. This effort led the VHA to undertake a major restructuring of its medical centers based upon the level of complexity of the surgical procedures provided. In 2010, the VHA issued directive 2010-018, Facility Infrastructure Requirements to Perform Standard, Intermediate, or Complex Surgical Procedures [33]. The NSQIP Operative Complexity Workgroup created a Surgical Complexity Matrix to classify Current Procedural Terminology (CPT) codes of surgical procedures into one of three categories: standard, intermediate, or complex [15]. Based on these analyses, each veterans hospital was assigned a surgical complexity level based on its clinical capabilities, facilities, equipment, caseload and staffing considerations. Individual VHA facilities faced with providing a non-emergent procedure beyond their designated level of complexity were charged with ensuring the safe and timely transfer of the patient to an appropriate VHA facility. It is important to emphasize that policy decisions and management procedures are highly centralized in the VHA system. While data from the Nationwide Inpatient Sample (NIS) indicates that 71 percent of patients in the U.S. reside in healthcare referral regions with high volume hospitals for Coronary Artery Bypass Graft (CABG), suggesting a high degree of regionalization for that specific procedure, no existing study has attempted to characterize the degree of regionalization for all complex surgeries in a large study population of civilian hospitals which are not centrally controlled as in the VHA. Therefore this research sought to describe the distribution of all hospital admissions characterized by their surgical complexity across a population of autonomous, non-governmental hospitals and to assess the implications of this distribution on complex surgical outcomes.

\section{Methods}

\section{Study design}

A retrospective, single year cross-sectional study was used to examine the distribution and selected outcomes associated with the relative complexity of surgical discharges in a study population of 200 hospitals. The hospitals were organized into quartiles based upon the number of complex surgical procedures performed in each hospital in order to provide a base analytic framework.

\section{Study population/setting}

The study used Florida Inpatient Discharge Data for the calendar year 2009 from the Florida Agency for Health Care Administration. Florida is a state with a large, racially and ethnically diverse population; a large number of non-governmental short-term acute hospitals; and a number of major metropolitan areas as well as many rural counties. This study (protocol 10-05-28) has been approved (exempt category 4) by the Institutional Review Board (IRB) for Research with Human Subjects, University of North Carolina at Charlotte. Independent variables of interest included patient age, gender, race, ethnicity, length of stay, number of procedures per patient, days from admission to procedure, type of admission, and hospital bed size and ownership. Principal and secondary diagnosis and procedure codes were used to derive two co-morbidity measures and to assign levels of complexity to each discharge with a surgical procedure.

\section{Surgical complexity}

We applied the Surgery Complexity Matrix developed by the VHA NSQIP Operative Complexity Workgroup to identify all discharges with a primary surgical procedure as standard, intermediate or complex [32]. Commercial software from Context Healthcare, Inc. was used to cross reference the International Classification of Diseases, Ninth Revision, Clinical Modification (ICD-9-CM) codes from the inpatient data source with the CPT-4 codes used in the VHA complexity matrix, allowing the examination of proportional surgical complexity at the hospital level.

\section{Co-morbidity measures}

To adjust for patient case mix, we used version 3.5 (January, 2010) of the co-morbidity software developed by Elixhauser and colleagues and distributed by Agency for Healthcare Research \& Quality (AHRQ) [17]. The output of this system is a count of the 30 binary variables (co-morbid conditions) found in each discharge record. Further, we used a modification of the Elixhauser co-morbidity measures to assign a single numeric score to each discharge derived by weighting the relative importance of each of the 30 co-morbidities [34].

\section{Main outcome measures}

ICD-9-CM Codes and the CCS System were used to identify all of the complex surgical procedures performed, and to allocate the complex surgical procedures across the hospital quartiles into 16 clinically meaningful categories. 
Paired hospital quartile differences were assessed for inhospital mortality and length-of-stay for matched surgical procedures.

\section{Statistical analyses}

Quartile differences in patient and hospital characteristics, as well as discharge complexity volumes, were assessed using Chi Square (categorical variables) and F-test and ANOVA (continuous variables).

To test the association of surgical complexity volume and mortality and LOS, we performed a propensity score match to account for patient differences in the surgical procedure, co-morbidity profile and mechanical ventilator use, as well as demographic characteristics including age, sex, race, and type of admission. Due to the extreme likelihood of death, patients diagnosed with acute renal failure were removed from the study population.

To accomplish the patient match a greedy algorithm was used to match cases to controls. The greedy match algorithm is frequently used for its ability to reduce the number of incomplete and inexact matches $[35,36]$. This algorithm matches cases with the highest precision match first and continues to perform matches until no additional matches are found. Sensitivity analyses were conducted to insure the integrity of the match.

Patient cohort matches were performed hierarchically between each quartile using the lower volume quartile as a base. Thus quartile1 patients were matched discreetly to similar patients in quartiles 2, 3 and 4. Quartile 2 patients were matched to quartiles 3 and 4 , and quartile 3 patients were only matched to quartile 4 patients. This process yielded six unique patient cohorts for comparison.

Using these matched cohorts, bivariate statistical methods were used to test the difference between the two patient populations. Chi-Square was used to test the mortality outcome, while Wilcoxon ranked sums was used for the length-of-stay outcome. All statistical analyses were performed using [SAS/STAT] software, Version [9.2 of the SAS System for [Windows]. Copyright @ 2002-2008 SAS Institute Inc. SAS and all other SAS Institute Inc. product or service names are registered trademarks or trademarks of SAS Institute, Inc., Cary, NC, USA.

\section{Results}

\section{Total discharges by procedure complexity}

There were just over 2.5 million discharges from 200 short-term acute hospitals in Florida in 2009. Across all hospitals, 1,044,975 (41.1\%) of these discharges involved no procedure and another 453,261 (17.8\%) involved a non-surgical procedure. Of the discharges which involved a surgical procedure, 336,280 (14.4\%) were considered to be of standard complexity, 504, 495 (19.8\%) of intermediate complexity, and 133, 436 (5.2\%) were in the complex category.

As complex procedure volumes increase across the four hospital quartiles, the percent of discharges with complex, intermediate, and non-surgical procedures increase; the percent of discharges with no procedure decreases; and, the percent of discharges with procedures of standard complexity is relatively uniform.

Quartile 1 hospitals discharged only $6.8 \%$ of all patients, an average of 3,445 discharges per hospital. Of these Q1 discharges, $56.1 \%$ had no procedure and only $1.5 \%$ involved a complex procedure. Q1 hospitals averaged only 51 complex procedures annually. By contrast quartile 4 hospitals discharged $49.8 \%$ of all patients, an average of 25,333 discharges per hospital. Of these Q4 discharges, $35.6 \%$ had no procedure and $7.4 \%$ involved a complex procedure. Q4 hospitals averaged 1,871 complex procedures annually. Therefore, Q4 hospitals had, on average, more than 7 times the number of discharges annually than Q1 hospitals but more than 36 times the number of discharges with complex procedures (Table 1).

\section{The distribution of complex discharges}

Of the 133,436 complex procedure discharges, Q1 accounted for only 1.9\%, Q2 7.5\%, Q3 20.5\%, and Q4 $70.1 \%$. A total 374 specific complex surgical procedures were identified in the transformation from CPT to ICD-9CM codes provided in the discharge data. Of these, 126 were performed in the lowest volume hospitals of Q1, 88 more were added in Q2 (total 214), 71 in Q3 (total 285) and another 89 procedures performed only in Q4 (total 374). Clearly, as hospitals provide a higher volume of complex procedures, the range of procedures also widens.

The CCS allocated the complex surgical procedures across the quartiles into 16 clinically meaningful categories. Eight of the CCS procedure categories did not have enough cases to represent at least $1 \%$ of the complex procedures within any quartile. The remaining 8 categories accounted for $97 \%$ of the complex procedures.

In four categories, the CCS procedure groups represented a smaller percentage of total complex procedures within the quartile as the overall volume increased: operations of the digestive system; operations of the respiratory system; operations of the integumentary system; and, operations of the musculoskeletal system. Viewed in another way, complex procedures in these categories are relatively decentralized and are proportionately more likely to occur in smaller rather than larger hospitals. Operations of the cardiovascular system, by contrast, represent higher percent of total complex procedures within the quartiles as volume increased (Figure 1).

Similarly, at the specific CCS procedure level, it is possible to see this same pattern. Small bowel resection and amputation of a lower extremity, for example, represent 
Table 1 Florida (2009) discharges by procedure complexity ${ }^{a}$

\begin{tabular}{|c|c|c|c|c|c|c|c|c|}
\hline \multicolumn{9}{|c|}{ Discharges with procedures } \\
\hline QTR s & Non-surgical & STAND & INT.M & $\mathrm{CO}$ & Un-assigned & Total procedures & No procedure & Total procedures \\
\hline QTR 1 & 19368 & 24479 & 25117 & 2568 & 4172 & 75704 & 96561 & 172265 \\
\hline $\mathrm{R} \%$ & $(11.2)$ & $(14.2)$ & $(14.6)$ & $(1.5)$ & $(2.4)$ & $(43.9)$ & $(56.1)$ & $(100.0)$ \\
\hline $\mathrm{C} \%$ & $(4.3)$ & $(7.3)$ & $(5.0)$ & (1.9) & $(5.9)$ & (5.1) & $(9.2)$ & $(6.8)$ \\
\hline \multirow[t]{3}{*}{ QTR 2} & 70291 & 56988 & 81055 & 9969 & 11188 & 229491 & 201214 & 430705 \\
\hline & $(16.3)$ & $(13.2)$ & $(18.8)$ & $(2.3)$ & $(2.6)$ & $(53.3)$ & $(46.7)$ & $(100.0)$ \\
\hline & $(15.5)$ & $(16.9)$ & $(16.1)$ & $(7.5)$ & $(15.9)$ & $(15.3)$ & $(19.3)$ & $(16.9)$ \\
\hline \multirow[t]{3}{*}{ QTR 3} & 109114 & 92730 & 131929 & 27364 & 16380 & 377517 & 295781 & 673298 \\
\hline & $(16.2)$ & (13.8) & (19.6) & $(4.1)$ & $(2.4)$ & $(56.1)$ & $(43.9)$ & $(100.0)$ \\
\hline & $(24.1)$ & (27.6) & $(26.1)$ & $(20.5)$ & $(23.2)$ & $(25.2)$ & $(28.3)$ & $(25.5)$ \\
\hline \multirow[t]{3}{*}{ QTR 4} & 254488 & 162083 & 266394 & 93535 & 38733 & 815233 & 451419 & 1266652 \\
\hline & $(20.1)$ & (12.8) & $(21.0)$ & (7.4) & (3.1) & $(64.4)$ & (35.6) & $(100.0)$ \\
\hline & $(56.1)$ & $(48.2)$ & $(52.8)$ & (70.1) & $(55.0)$ & $(54.4)$ & $(43.2)$ & $(49.8)$ \\
\hline \multirow[t]{3}{*}{ Total } & 453261 & 336280 & 504495 & 133436 & 70473 & 1497945 & 1044975 & 2542920 \\
\hline & (17.8) & $(14.4)$ & (19.8) & $(5.2)$ & (2.8) & $(58.9)$ & $(41.1)$ & \\
\hline & $(100.0)$ & $(100.0)$ & $(100.0)$ & (100.0) & $(100.0)$ & $(100.0)$ & $(100.0)$ & (100.0) \\
\hline
\end{tabular}

Abbreviations: R\% Row Percentage, C\% Column Percentage, QTR Quartile, Stand Standard, Int. M Intermediate, Co Complex.

${ }^{a}$ Expressed as number (percentage) unless otherwise indicated. Percentages may not total 100 because of rounding.

a higher percent of the complex surgeries in lower volume hospitals. Heart valve procedures and CABG, as well as incision and excision of the Central Nervous System (CNS), represent a higher percent of complex surgeries in the higher volume hospitals. Organ transplant and certain other diagnostic and therapeutic procedures are limited to quartile 4 hospitals (Figure 2).

\section{Mortality and length of stay outcomes}

The six matched patient cohorts showed no statistically significant differences in in-hospital mortality (Table 2). It is worth emphasizing that the matched quartile comparisons were adjusted for the types of procedure, comorbidities and patient age, race, sex and type of admission. Therefore, the mortality comparisons between the smallest

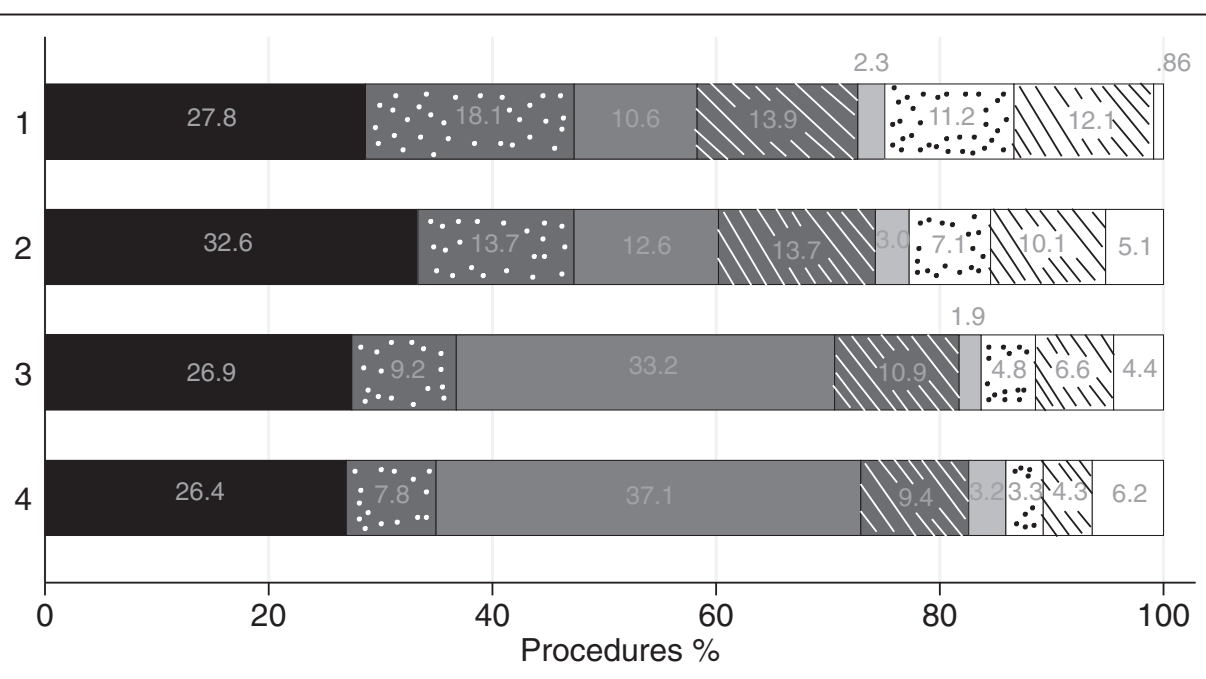

\begin{tabular}{|c|c|c|c|}
\hline & Nervous System & $\because: \because \cdot \div$ & Respiratory System \\
\hline & Cardiovascular System & MININ & Digestive System \\
\hline & Urinary System & ::::::::: & Musculoskeletal System \\
\hline & Integumentary System & & Miscellaneous Procedures \\
\hline
\end{tabular}

Figure 1 Distribution of complex surgical procedures by quartiles. 


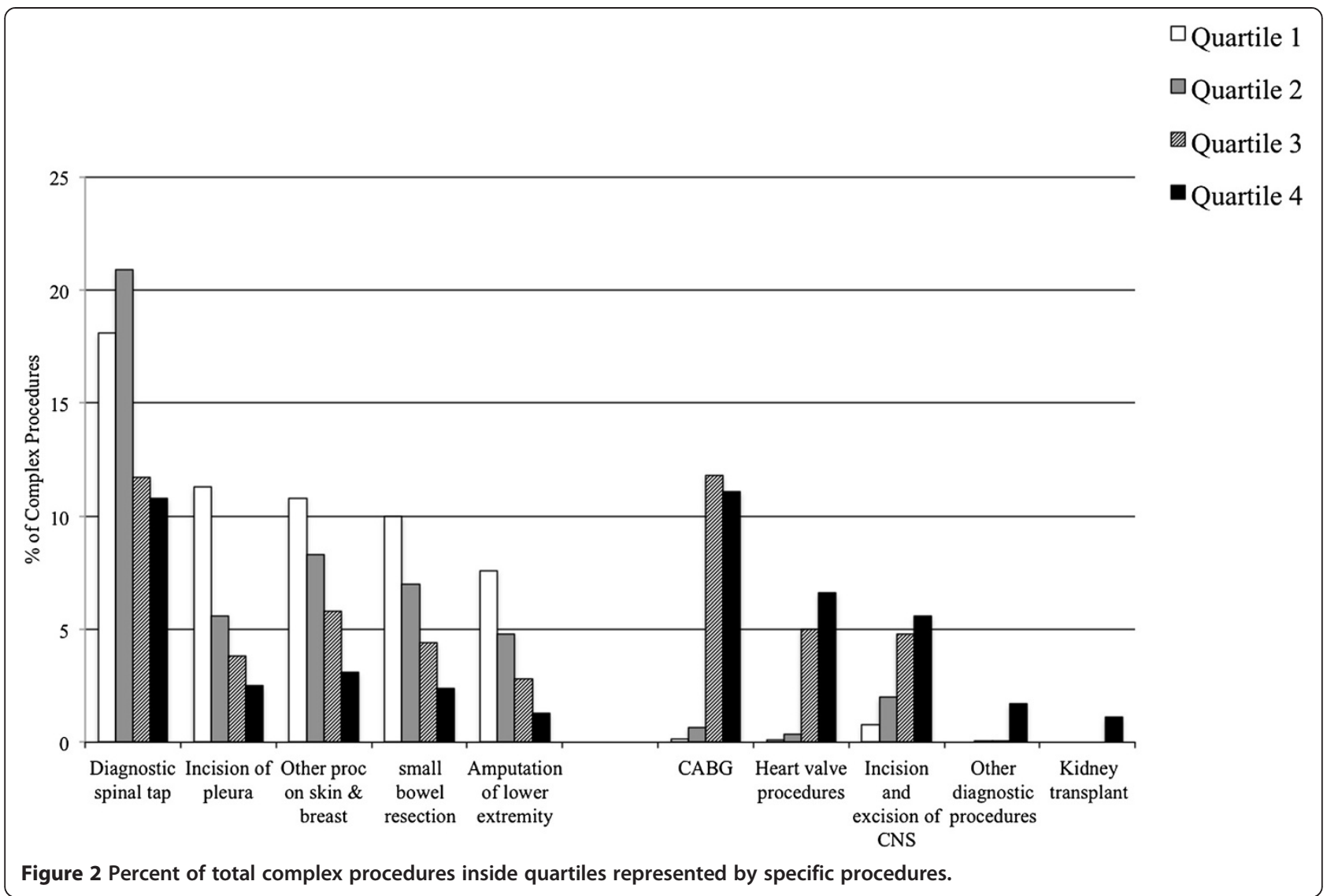

and largest hospitals (quartiles 1 and 4) only involved the narrower range of complex procedures being performed in the smallest hospitals. For these procedures, the higher total volumes of all complex procedures occurring in the largest hospitals provide no mortality advantage.

Length-of-stay for the matched patient cohorts shows an increasing length of stay as the volume of complex procedures increases, with three exceptions. The LOS differences between quartiles 1 and 2 and 1 and 3 are not significant. In contrast, the LOS difference between quartiles 2 and 3 is significant but reversed (i.e., LOS in quartile 2 is larger than quartile 3). The LOS gap between the smallest and largest hospitals is about a full day (Table 3).

\section{Discussion}

Complex surgeries in Florida hospitals represent only about five percent of total discharges but they are highly concentrated, disproportionate even to the relative concentration of total discharges. There is also a hierarchy of regionalization in which certain complex procedures are performed only in hospitals that attain complex surgery

Table 2 Propensity score match comparison: hospital mortality by complex surgery quartile

\begin{tabular}{|c|c|c|c|c|c|c|c|}
\hline Mortality & Matched $^{a}$ & Based $^{b}$ & Comparison & Base (\%) & Comparison (\%) & & ficance \\
\hline Quartile comparison & Population size & Mortalities & Mortalities & Mortality $\mathrm{R}$ & Mortality R & $\overline{\mathrm{Chi}^{2}}$ & $\operatorname{Pr}>\mid \mathrm{Chi}^{2}$ \\
\hline 1 vs. 4 & 2916 & 20 & 15 & 1.4 & 1.0 & 0.72 & 0.39 \\
\hline 1 vs. 3 & 2476 & 12 & 15 & 1.0 & 1.2 & 0.33 & 0.56 \\
\hline 1 vs. 2 & 2152 & 11 & 8 & 1.0 & 0.7 & 0.47 & 0.48 \\
\hline 2 vs. 4 & 11692 & 49 & 68 & 0.8 & 1.2 & 3.11 & 0.07 \\
\hline 2 vs. 3 & 9798 & 44 & 40 & 0.9 & 0.8 & 0.19 & 0.66 \\
\hline 3 vs. 4 & 16205 & 97 & 222 & 2.4 & 2.7 & 1.51 & 0.21 \\
\hline
\end{tabular}

Abbreviation: Mortality $R$ Mortality Rate.

${ }^{\mathrm{a}}$ Matched Population base divided by two = quartile population.

${ }^{b}$ Base mean represents the average mortality rate for the base quartile. 
Table 3 Propensity score match comparison: median length of stay by complex surgery quartile

\begin{tabular}{|c|c|c|c|c|c|c|c|c|c|c|}
\hline \multirow{2}{*}{$\begin{array}{c}\text { Length of stay } \\
\text { Quartile comparison }\end{array}$} & \multirow{2}{*}{$\begin{array}{c}\text { Matched }^{\mathrm{a}} \\
\text { Population size }\end{array}$} & \multicolumn{3}{|c|}{ Based $^{\mathbf{b}}$} & \multicolumn{3}{|c|}{ Comparison } & \multirow{2}{*}{$\begin{array}{c}\text { Mean diff } \\
\text { Mean diff }{ }^{c}\end{array}$} & \multicolumn{2}{|c|}{ Significance $^{d}$} \\
\hline & & Mean & Std & Median & Mean & Std & Median & & Z Value & $\operatorname{Pr}>|z|$ \\
\hline 1 vs. 4 & 2916 & 5.5 & 5.53 & 4 & 6.4 & 7.43 & 4 & 0.98 & 2.94 & 0.00 \\
\hline 1 vs. 3 & 2476 & 5.7 & 6.53 & 4 & 6.2 & 5.20 & 4 & 0.56 & 1.73 & 0.08 \\
\hline 1 vs. 2 & 2152 & 5.2 & 5.76 & 4 & 5.3 & 5.53 & 4 & 0.07 & -0.08 & 0.93 \\
\hline 2 vs. 4 & 11692 & 5.5 & 8.76 & 3 & 6.2 & 10.54 & 4 & 0.75 & -5.43 & $<.001$ \\
\hline 2 vs. 3 & 9798 & 5.3 & 8.09 & 3 & 5.0 & 6.67 & 3 & -0.29 & -2.05 & 0.04 \\
\hline 3 vs. 4 & 16205 & 5.8 & 7.47 & 4 & 6.2 & 8.85 & 4 & 0.41 & 4.98 & $<.001$ \\
\hline
\end{tabular}

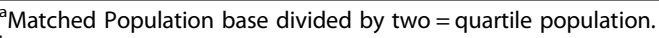

${ }^{\mathrm{b}}$ Base median represents the median LOS for the base quartile.

${ }^{\mathrm{c}}$ Median difference = comparison median-base median.

${ }^{\mathrm{d}}$ Significance test is Wilcoxon Rank Sum (2-sided).

volume thresholds. As a result, the overall composition of complex surgery caseloads vary among hospitals as volume increases. From a quality perspective, these results provide evidence that both formal and informal methods of regionalization in Florida are generally allocating complex surgeries among hospitals in a manner consistent with the capabilities of each facility.

Private sector efforts to regionalize or concentrate complex surgeries have been less comprehensive and much more "procedure specific" than the VHA program. Further, approaches to enhancing volumes for complex surgeries can be characterized as either formal or informal. Formal regionalization can be inferred to mean a deliberate geographic centralization of surgical services via governmental regulatory authority, such as state Certificate-of-Need (CON) laws [37]. Informal regionalization has been defined as the concentration of select patient populations at specific local centers as a result of selective, historic, or de facto referral patterns to those centers by providers [38]. The selective referral of patients resulting from informal regionalization is based on decentralized decisions by individual providers and natural market dynamics and is not mandated by formal legal or administrative organizations.

The characteristics of complex surgeries and the methods utilized in this analysis suggest caution in the interpretation of these results. With only a few exceptions (e.g. CABG), complex surgical procedures occur infrequently and therefore represent a low volume overall. This means that, for certain procedures, even the highest volume hospitals will perform the procedure a modest number of times. For analyses of the relationship between specifically defined procedure volumes and outcomes, the quartile comparison approach utilized in this analysis would be inadequate since most of the hospitals in these comparisons would likely be drawn from the highest volume hospitals in quartiles 3 and 4. Another important limitation in this study involves the use of the propensity score match algorithm which is applied to all complex procedures in the base (i.e. lower volume) quartile. Because of the very low volume of many complex procedures performed in quartiles 1 and 2, and the multiple covariates utilized in the matching, many complex procedures were not included in the volume/outcome comparisons. A major focus of quality monitoring of complex procedures should be on the procedures which are rarely done in the smallest volume hospitals, but nonetheless do infrequently occur. Our analytical approach was unable to address this problem.

\section{Conclusions}

Complex surgery in Florida is effectively regionalized likely as the results of both formal and informal influences. Small volume hospitals operating within the range of complex procedures appropriate to their capabilities provide no increased risk of post surgical mortality.

\section{Abbreviations}

AHRQ: Agency for healthcare research \& quality; CABG: Coronary artery bypass grafting; CCS: Clinical classification software; CNS: Central nervous system; CON: Certificate-of-need; CPT: Current procedural terminology; ICD-9-CM: International classification of diseases, ninth revision, clinical modification; NIS: Nationwide inpatient sample; NSQIP: National surgical quality improvement program; LOS: Length of stay; US: United States; VHA: Veterans health administration.

\section{Competing interests}

The authors declare that they have no competing interests.

\section{Authors' contributions}

JS: Integrity of the work as a whole. JS and CC were involved in the conception and design of the study. JS and JWF were responsible for the acquisition of data. JS, CMB, CC, and SS performed the analysis and interpretation of data. JS and CC wrote the draft of the manuscript. All authors critically reviewed and gave final approval to the manuscript.

\section{Funding}

This study was partially supported by the Office of the Secretary, US Department of Health and Human Services, Office of Healthcare Quality (agreement\# OS58124).

\section{Author details}

${ }^{1}$ Department of Public Health Sciences, College of Health and Human Services, University of North Carolina, Charlotte, NC, USA. ${ }^{2}$ College of Health and Human Services, University of North Carolina, Charlotte, NC, USA.

Received: 24 July 2013 Accepted: 7 August 2014

Published: 16 August 2014 


\section{References}

1. Barshes NR, McPhee J, Ozaki CK, Nguyen LL, Menard MT, Gravereaux E, Belkin $\mathrm{M}$ : Increasing complexity in the open surgical repair of abdominal aortic aneurysms. Ann Vasc Surg 2012, 26(1):10-17.

2. Chaney MA, Durazo-Arvizu RA, Fluder EM, Sawicki KJ, Nikolov MP, Blakeman BP, Bakhos M: Port-access minimally invasive cardiac surgery increases surgical complexity, increases operating room time, and facilitates early postoperative hospital discharge. Anesthesiology 2000, 92(6):1637-1645.

3. Chow WB, Bilmoria KY, Hall BL, Ko CY: An objective system for measuring surgical complexity in elderly patients. J Surg Res 2012, 172(2):214.

4. Deyo RA, Mirza SK, Martin BI, Kreuter W, Goodman DC, Jarvik JG: Trends, major medical complications, and charges associated with surgery for lumbar spinal stenosis in older adults. JAMA 2010, 303(13):1259-1265.

5. Donati A, Cornacchini O, Loggi S, Caporelli S, Conti G, Falcetta S, Alò F, Pagliariccio G, Bruni E, Preiser JC, Pelaia P: A comparison among portal lactate, intramucosal sigmoid $\mathrm{Ph}$, and deltaCO2 ( $\mathrm{PaCO} 2$ - regional $\mathrm{PcO} 2)$ as indices of complications in patients undergoing abdominal aortic aneurysm surgery. Anesth Analg 2004, 99(4):1024-1031.

6. Dranove D, Gron A: Effects of the malpractice crisis on access to and incidence of high-risk procedures: evidence from Florida. Health Aff 2005, 24(3):802-810

7. Eagle KA, Berger PB, Calkins H, Chaitman BR, Ewy GA, Fleischmann KF, Fleisher LA, Froehlich JB, Gusberg RJ, Leppo JA, Ryan T, Schlant RC, Winters WL Jr, Gibbons RJ, Antman EM, Alpert JS, Faxon DP, Fuster V, Gregoratos G, Jacobs AK, Hiratzka LF, Russell RO, Smith SC Jr: ACC/AHA guideline update for perioperative cardiovascular evaluation for noncardiac surgeryexecutive summary. A report of the American College of Cardiology/ American Heart Association Task Force on Practice Guidelines (committee to update the 1996 guidelines on perioperative cardiovascular evaluation for noncardiac surgery). Anesth Analg 2002, 94(5):1052-1064.

8. Ergina PL, Cook JA, Blazeby JM, Boutron I, Clavien PA, Reeves BC, Seiler CM: Challenges in evaluating surgical innovation. Lancet 2009, 374(9695):1097-1104.

9. Guzzo MH, Landercasper J, Boyd WC, Lambert PJ: Outcomes of complex gastrointestinal procedures performed in a community hospital. WMJ 2005, 104(6):30-34

10. Moran BJ: Decision-making and technical factors account for the learning curve in complex surgery. J Public Health 2006, 28(4):375-378.

11. Palese A, Bresadola V, Lorenzis K, Costaperaria G, Comuzzi C: Indicators that affect the complexity of surgical patients care. The nurses' view. Assist Inferm Ric 2004, 23(4):212-220.

12. Pillai SB, van Rij AM, Williams S, Thomson IA, Putterill MJ, Greig S: Complexity- and risk-adjusted model for measuring surgical outcome. Br J Surg 1999, 86(12):1567-1572.

13. Schoonhoven CB, Scott WR, Flood AB, Forrest WHJ: Measuring the complexity and uncertainty of surgery and postsurgical care. Med Care 1980, 18(9):893-915.

14. Tomaszewski JE, Abraham S, Bell K, Mourelatos Z, Reynolds C, Seykora J, LiVolsi VA: The measurement of complexity in surgical pathology. Am J Clin Pathol 1996, 106(4 Suppl 1):S65-S69.

15. Aust JB, Henderson W, Khuri S, Page CP: The impact of operative complexity on patient risk factors. Ann Surg 2005, 241(6):1024-1027.

16. Detsky AS, Abrams HB, McLaughlin JR, Drucker DJ, Sasson Z, Johnston N, Scott JG, Forbath N, Hilliard JR: Predicting cardiac complications in patients undergoing non-cardiac surgery. J Gen Intern Med 1986, 1(4):211-219.

17. Elixhauser A, Steiner C, Harris DR, Coffey RM: Comorbidity measures for use with administrative data. Med Care 1998, 36(1):8-27.

18. Makary MA, Segev DL, Pronovost PJ, Syin D, Bandeen-Roche K, Patel P, Takenaga R, Devgan L, Holzmueller CG, Tian J, Fried LP: Frailty as a predictor of surgical outcomes in older patients. J Am Coll Surg 2010, 210(6):901-908.

19. Planells Roig M, Cervera Delgado M, Bueno Lledo J, Sanahuja Santaf A Garcia Espinosa R, Carbo Lopez J: Surgical Complexity Classification Index (SCCl): a new patient classification system for clinical management of laparoscopic cholecystectomy. Cir Esp 2008, 84(1):37-43.

20. Story DA: Postoperative mortality and complications. Best Pract Res Clin Anaesthesiol 2011, 25(3):319-327.

21. Aletti GD, Dowdy SC, Podratz KC, Cliby WA: Relationship among surgical complexity, short-term morbidity, and overall survival in primary surgery for advanced ovarian cancer. Am J Obstet Gynecol 2007, 197(6):676.e1-676. e7. http://dx.doi.org/10.1016/j.ajog.2007.10.495.
22. Auerbach AD, Maselli J, Carter J, Pekow PS, Lindenauer PK: The relationship between case volume, care quality, and outcomes of complex cancer surgery. J Am Coll Surg 2010, 211(5):601-608.

23. Bojan M, Gerelli S, Gioanni S, Pouard P, Vouhe P: Comparative study of the Aristotle comprehensive complexity and the risk adjustment in congenital heart surgery scores. Ann Thorac Surg 2011, 92(3):949-956.

24. Dimick JB, Pronovost PJ, Cowan JA Jr, Lipsett PA, Stanley JC, Upchurch GR $\mathrm{Jr}$ : Variation in postoperative complication rates after high-risk surgery in the United States. Surgery 2003, 134(4):534-540.

25. Eveleigh M, Blencowe N, Mills N, Blazeby J: Understanding the complexity of surgical procedures in RCTs: a pilot study to test the application of the MRC framework for evaluating complex healthcare interventions in the operating theatre. Trials 2011, 12(Suppl 1):A148.

26. Goodney PP, Stukel TA, Lucas FL, Finlayson EV, Birkmeyer JD: Hospital volume, length of stay, and readmission rates in high-risk surgery. Ann Surg 2003, 238(2):161-167.

27. Gordon TA, Bowman HM, Bass EB, Lillemoe KD, Yeo CJ, Heitmiller RF, Choti MA, Burleyson GP, Hsieh G, Cameron JL: Complex gastrointestinal surgery: impact of provider experience on clinical and economic outcomes. J Am Coll Surg 1999, 189(1):46-56.

28. Holt NF, Mukherjee A, Schonberger RB, Silverman DG: Impact of ASA physical status and surgical complexity on length of stay and hospital charges. Anesthesiology 2006, 105(A195):A195.

29. Nguyen NT, Paya M, Stevens CM, Mavandadi S, Zainabadi K, Wilson SE: The relationship between hospital volume and outcome in bariatric surgery at academic medical centers. Ann Surg 2004, 240(4):586.

30. Simunovic M, Urbach D, Baxter N, Davis D, Levine MN: Assessing the volume-outcome hypothesis and region-level quality improvement interventions: pancreas cancer surgery in two Canadian Provinces. Ann Surg Oncol 2010, 17(10):2537-2544

31. Halm EA, Lee C, Chassin MR: Is volume related to outcome in health care? A systematic review and methodologic critique of the literature. Ann Intern Med 2002, 137(6):511-520.

32. U.S. Department of Veterans Affairs, Veterans Health Administration, Office of Inspector General: Healthcare Inspection: A Review of Facility Capabilities Where Veterans Received Complex Surgical Care. Washington, DC; 2011. http://www.va.gov/oig/54/reports/VAOIG-10-02302-225.pdf.

33. U.S. Department of Veterans Affairs, Veterans Health Administration: Facility Infrastructure Requirements to Perform Standard, Intermediate, or Complex Surgical Procedures. Washington, DC; 2010. http://www.va.gov/ vhapublications/ViewPublication.asp?pub ID=2227.

34. Van Walraven C, Austin PC, Jennings A, Quan H, Forster AJ: A modification of the Elixhauser comorbidity measures into a point system for hospita death using administrative data. Med Care 2009, 47(6):626-633. doi:10.1097/MLR.0b013e31819432e5

35. Parsons LS: Reducing bias in a propensity score matched pair sample using greedy matching techniques. In Proceedings of the Twenty-Sixth SAS Users Group International Conference. Cary, NC: SAS Institute Inc; 2013:1166-1171.

36. Rosenbaum PR, Rubin DB: Constructing a control group using multivariate matched sampling methods that incorporate the propensity score. Am Stat 1985, 39(1):33-38

37. Nallamothu BK, Eagle KA, Ferraris VA, Sade RM: Should coronary artery bypass grafting be regionalized? Ann Thorac Surg 2005, 80:1572-1581. doi:10.1016/j.athoracsur.2005.04.003

38. Glickman SW, Delgado MK, Hirshon JM, Hollander JE, Iwashyna TJ, Jacobs AK Kilaru AS, Lorch SA, Mutter RL, Myers SR, Owens PL, Phelan MP, Pines JM, Seymour CW, Ewen Wang N, Branas CC: Defining and measuring successful emergency care networks: a research agenda. Acad Emerg Med 2010, 17(12):1297-1305.

doi:10.1186/1471-2482-14-55

Cite this article as: Studnicki et al: A cross-sectional retrospective analysis of the regionalization of complex surgery. BMC Surgery 2014 14:55. 